\title{
IMOBILIZAÇÃO DE COLÁGENO HUMANO TIPO I EM MEMBRANAS DE NANOCELULOSE BACTERIANA
}

\author{
A. C. J. MEYER ${ }^{1}$, E. M. REIS ${ }^{1}$ e L. M. PORTO ${ }^{1}$ \\ ${ }^{1}$ Universidade Federal de Santa Catarina, Departamento de Engenharia Química e Alimentos \\ E-mail para contato: \{ana_meyer, emily_reis, luismar\}@intelab.ufsc.br
}

\begin{abstract}
RESUMO - O uso de biomateriais na cicatrização de feridas têm crescido extensivamente na tentativa de suprir as necessidades não atendidas por curativos convencionais. A utilização de plataformas de nanocelulose bacteriana (BNC) torna-se interessante devido às propriedades desse hidrogel. $\mathrm{O}$ objetivo desse estudo foi a imobilização de colágeno, uma proteína que participa diretamente da cicatrização de feridas, em membranas de BNC visando produzir biomateriais capazes de acelerar o processo de cicatrização. A imobilização foi feita através da conversão dos grupos hidroxila da BNC a grupos carboxílicos e sua posterior ativação para que se ligassem ao grupamento amina do colágeno. Imagens de microscopia eletrônica de varredura (MEV) permitiram a visualização das fibras de colágeno na membrana produzida e a análise por espectroscopia de infravermelho com transformada de Fourier confirmou a presença dos grupos funcionais previstos. Quando testado quanto à citotoxicidade, o material se provou não citotóxico e consequentemente com potencial para ser testado na reparação tecidual.
\end{abstract}

\section{INTRODUÇÃO}

A cicatrização de feridas envolve uma série de interações entre mediadores de citocinas, diferentes tipos de células e os componentes da matriz extracelular (MEC) no decorrer das fases da cicatrização (Brett, 2008). Para auxiliar o processo, tratamentos adequados são fundamentais. Os métodos mais comuns utilizam materiais que visam não deixar as feridas expostas e manter o meio úmido, para evitar traumas, reduzir a dor, aumentar a vascularização e promover a cicatrização (Field, Kerstein, 1994).

Biopolímeros são amplamente utilizados em medicina regenerativa como curativos alternativos para feridas e queimaduras, devido à sua biocompatibilidade, biodegradabilidade, baixo custo e semelhança com a MEC (Balakrishnan, Jayakrishnan, 2005). A nanocelulose bacteriana (BNC) é um biopolímero que possui nanoestrutura fibrilar semelhante à MEC (Rambo et al., 2008). Sua estrutura porosa tridimensional confere-lhe propriedades únicas, como a alta capacidade de retenção de água, resistência mecânica, alta porosidade e biocompatibilidade (Klemm et al., 2011; Trovatti et al., 2011). Devido a estas propriedades, existe um crescente interesse de pesquisa no desenvolvimento de materiais com aplicação em cicatrização de feridas e queimaduras (Muangman et al., 2011; Kwak et al., 2015). No entanto, a BNC tem baixa bioatividade e atividade química se comparado à MEC. Assim, a 
introdução de grupos ativos na superfície das nanofibras da BNC é necessária para melhorar o desempenho deste material na reparação tecidual.

O colágeno, principal componente da MEC, tem sido indicado como acelerador do processo de cicatrização (Lee et al., 2001), auxiliando na migração e estratificação das camadas de células como fibroblastos e queratinócitos (Brett, 2008). Por esse motivo, muitos autores já trabalharam com algum tipo de material polimérico e colágeno (Lu et al., 2014, Souza, 2015), entretanto, as ligações físicas que foram realizadas para a produção desses materiais não são tão eficientes quanto as ligações químicas - sendo estas mais eficazes quando se visa um processo de cicatrização prolongado. Assim, o objetivo deste trabalho foi a funcionalização de membranas de BNC com colágeno humano tipo I (COL) para o desenvolvimento de um material com propriedades aplicáveis a cicatrização de feridas.

\section{MATERIAIS E MÉTODOS}

\subsection{Materiais}

Todos os reagentes foram comprados de Sigma-Aldrich Brasil Ltd. e utilizados conforme recebidos, exceto quando mencionado.

\subsection{Produção da BNC}

As membranas de BNC foram produzidas pelo cultivo da bactéria Gluconacetobacter hansenii, ATCC 23769. Primeiramente, $100 \mu \mathrm{L}$ de inóculo foram plaqueados em meio manitol ágar. Após 7 dias de cultivo a $26{ }^{\circ} \mathrm{C}, 30$ colônias isoladas foram selecionadas e inoculadas em $5 \mathrm{~mL}$ de meio manitol $\left(25 \mathrm{~g} \cdot \mathrm{L}^{-1}\right)$, extrato de levedura $\left(5,0 \mathrm{~g} \cdot \mathrm{L}^{-1}\right)$ e peptona $(3,0$ g. $\left.\mathrm{L}^{-1}\right)$, esterilizado $(\mathrm{pH} 6,5)$. Subsequentemente, $5 \mathrm{~mL}$ do inóculo foram adicionados à $45 \mathrm{~mL}$ de meio manitol e a solução foi transferida para placas de 24 poços $(1 \mathrm{~mL} /$ poço $)$ e mantida em cultura estática à $26^{\circ} \mathrm{C}$ durante 4 dias. No fim, as membranas formadas foram removidas e purificadas em $\mathrm{NaOH}(0,1 \mathrm{M})$ à $50^{\circ} \mathrm{C}$ por $24 \mathrm{~h}$ e finalmente lavadas com água destilada até atingirem $\mathrm{pH} 6,5$.

\subsection{Produção da BNC-COL}

As membranas de BNC produzidas na etapa anterior foram oxidadas com $\mathrm{HNO}_{3} / \mathrm{H}_{3} \mathrm{PO}_{4}-\mathrm{NaNO}_{2}$ como descrito por Kumar e Yang (2002), para converter os grupos hidroxilas livres da BNC em grupos carboxilas. As membranas foram imersas em uma solução de ácido nítrico e ácido fosfórico 2:1 (v/v) e após foi acrescentado nitrito de sódio $(\mathrm{p} / \mathrm{v})$. A mistura permaneceu com leve agitação, em ambiente sem a presença de luz, por $24 \mathrm{~h}$. Posteriormente, as membranas oxidadas (BNC-OX) foram transferidas para uma solução $0,2 \%(\mathrm{p} / \mathrm{p})$ de glicerol durante 15 minutos para remover o oxidante. Por fim, foram lavadas com acetona e deixadas secar por 30 minutos a $25^{\circ} \mathrm{C}$.

A imobilização de colágeno foi realizada conforme retratado por Liu e colaboradores (2005) e Li e colaboradores (2008). Resumidamente, as membranas BNC-OX foram imersas em tampão 0,02M de MES (ácido 2-morfolinoetanosulfónico monohidratado), pH 4,5, contendo EDC (1-etil-3-(3-dimetilaminopropil) carbodiimida)/NHS (N-hidroxisuccinimida) 
0,01M (1:1) durante $24 \mathrm{~h} \mathrm{a} 4{ }^{\circ} \mathrm{C}$ com agitação, para a ativação dos grupos carboxílicos de BNC-OX. Após, as membranas foram imersas em uma solução de $0,1 \cdot \mathrm{mg} \cdot \mathrm{mL}^{-1}$ de colágeno humano tipo I por $24 \mathrm{~h}$ à $4{ }^{\circ} \mathrm{C}$. As membranas resultantes (BNC-COL) foram lavadas com PBS três vezes e posteriormente foi realizada uma última lavagem com água deionizada.

\subsection{Caracterização da $\mathrm{BNC}-\mathrm{COL}$}

A técnica de espectroscopia de infravermelho com transformada de Fourier (FTIR) foi utilizada para confirmar a presença de alterações específicas dos grupos funcionais em BNCCOL. Os espectros de infravermelho foram registrados em um espectrofotômetro Agilent (modelo Carry 600), com resolução de $4 \mathrm{~cm}^{-1}$, no intervalo de $4000-600 \mathrm{~cm}^{-1}$. Além disso, foi realizada a analise morfológica da superfície das membranas por microscopia eletrônica de varredura (MEV) através do aparelho JEOL JSM-6390LV operando a 10kV.

\subsection{Citotoxicidade}

A citotoxicidade das membranas $\mathrm{BNC}-\mathrm{COL}$ foi avaliada por contato direto, de acordo com a ISO 10993-05. Membranas de BNC foram utilizadas como controle. Fibroblastos de camundongo imortalizados (L929) foram cultivados em DMEM (Dulbecco's Modified Eagle's Medium) suplementado com $10 \%$ de soro fetal bovino e $1 \%$ de penicilina/estreptomicina. As células foram cultivadas com uma densidade de $9 \times 10^{3}$ células $\cdot \mathrm{cm}^{-2}$ em placas de 24 poços por $24 \mathrm{~h} \mathrm{em}$ ambiente contendo $5 \% \mathrm{CO}_{2}$ à $37{ }^{\circ} \mathrm{C}$. Posteriormente, membranas de BNC e BNC-COL foram adicionadas aos poços. Após 1, 3 e 7 dias de cultura a atividade metabólica das células foi avaliada pelo ensaio de MTS [3- (4,5dimetiltiazol-2-il) -5-(3-carboximetoxifenil)-2-(4-sufofenil)-2H-tetrazólio] de acordo com as instruções (Promega Biotecnologia do Brasil, Ltda. (São Paulo, SP)). As placas de cultura foram mantidas em uma atmosfera umidificada a $5 \%$ de $\mathrm{CO}_{2}$ à $37{ }^{\circ} \mathrm{C}$ durante $2 \mathrm{~h}$. A absorbância das soluções sobrenadantes foi medida por leitor Micro ELISA a $490 \mathrm{~nm}$.

\section{RESULTADOS E DISCUSSÃO}

\subsection{Caracterização da $\mathrm{BNC}-\mathrm{COL}$}

A Figura 1 apresenta os espectros de FTIR das membrana de BNC e BNC-COL. O espectro da BNC apresenta bandas características desse material, onde a banda de absorção atribuída ao grupo hidroxila e a ligação de hidrogênio é observada em $3343 \mathrm{~cm}^{-1}$ (Choi et al., 2004), presente também em BNC-COL. A confirmação da imobilização de colágeno nas membranas BNC-COL é feita através da identificação do grupamento amida I a $1652 \mathrm{~cm}^{-1}$, além das bandas para amida II e III em $1523 \mathrm{~cm}^{-1}$ e $1236 \mathrm{~cm}^{-1}$ (Payne; Veis, 1988), respectivamente.

A morfologia da superfície das membranas foi analisada por MEV. A Figura 2a apresenta uma típica imagem de BNC, onde observa-se uma estrutura tridimensional bem organizada com poros interconectados, formada por uma rede entrelaçada de nanofibras. Essas características foram preservadas após a imobilização do colágeno, como pode ser visto na Figura 2b. Sendo assim, as propriedades e a aplicabilidade da BNC, que se devem às características citadas (Klemm et al., 2011; Trovatti et al., 2011), continuam presentes em BNC-COL. Nessa membrana, as fibras de colágeno aparentam estar dispostas de maneira 


\section{Congresso Brasileiro de Engenharia Química em Iniciação Científica UFSCar - São Carlos - SP 16 a 19 de Julho de 2017}

irregular, estando tanto na superfície como preenchendo a estrutura da nanocelulose. Os cristais que estão presentes na Figura $2 \mathrm{~b}$ correspondem à presença de $\mathrm{NaCl}$, como observado por Souza (2015).

Figura 1 - FTIR das membranas BNC e BNC-COL.

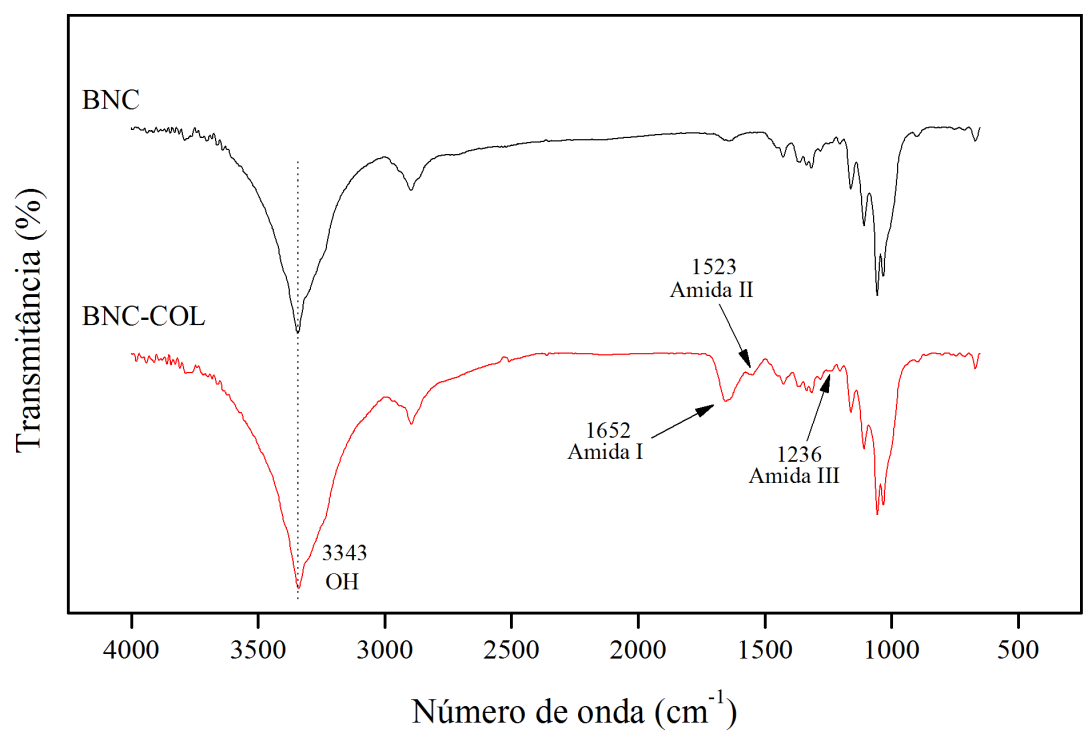

Figura 2 - MEV da superfície das membranas (a) BNC e (b) BNC-COL.
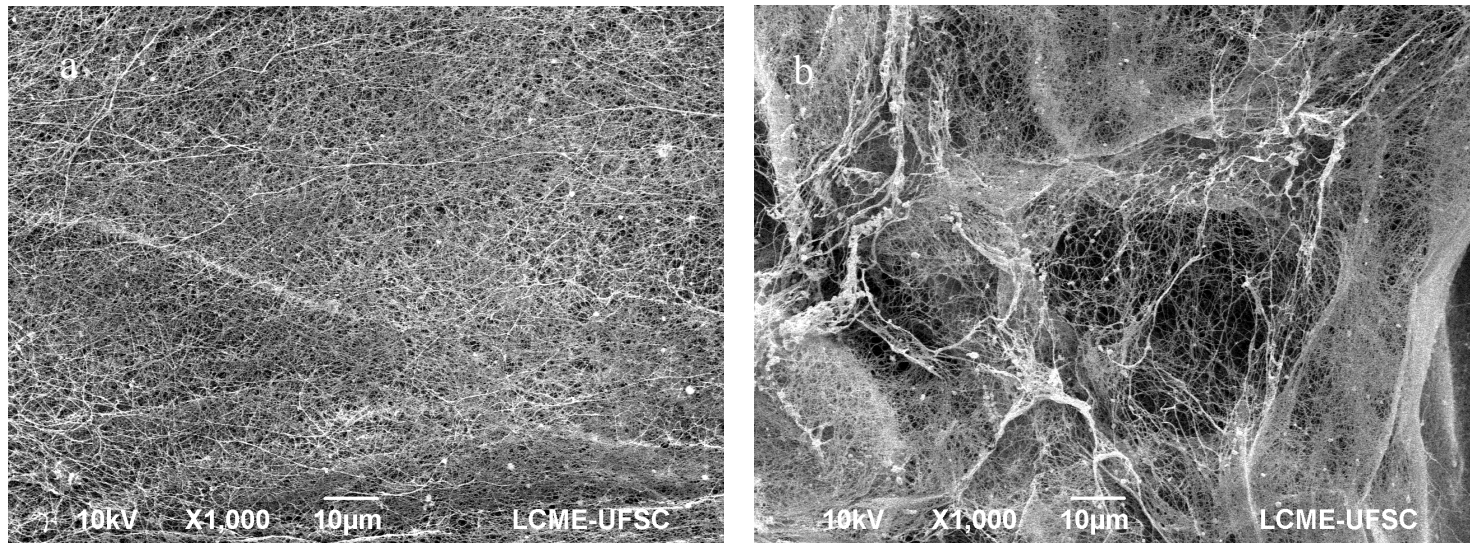

\subsection{Citotoxicidade da BNC-COL}

As membranas de BNC são consideradas materiais não citotóxicos, como constatado por Czaja e colaboradores (2007). Para analisar se a imobilização do colágeno interfere no potencial citotóxico das membranas de $\mathrm{BNC}$ foi realizado um ensaio de citotoxicidade. Os resultados obtidos através do teste de MTS mostraram que as membranas de BNC e BNCCOL não induziram uma resposta citotóxica após 7 dias em contato com as células, de acordo com a norma ISO-10993-5: 2009. Após 1 e 3 dias de cultura, a atividade metabólica das membranas em contato com BNC e BNC-COL foram semelhantes. Entretanto, depois de 7 dias de cultura, houve um aumento significativo de $99,8 \%$ da atividade metabólica das células em contato com BNC-COL, se comparado à BNC (Figura 3). 
Figura 3 - Atividade metabólica de células L929 após contato direto com as membranas de $\mathrm{BNC}$ e BNC-COL por 7 dias. * Diferença significativa, $\mathrm{P}<0.05$.

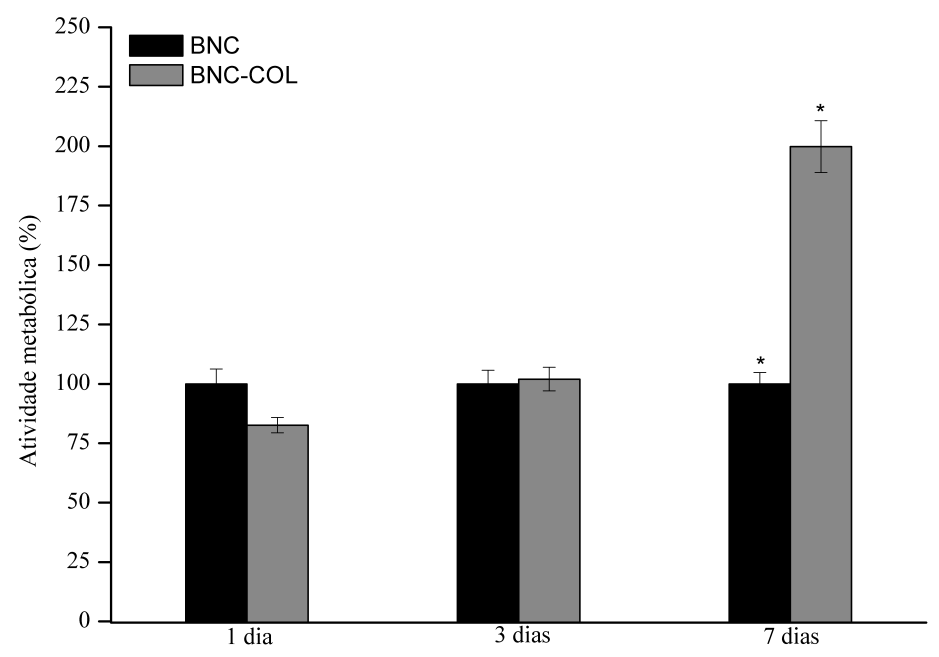

\section{CONCLUSÃO}

As membranas BNC-COL foram obtidas através de ligações covalentes entre os grupamentos amina do colágeno e carboxílicos da BNC. Os resultados do FTIR confirmaram a imobilização química do colágeno nas membranas produzidas e as imagens de MEV mostraram que essa imobilização não alterou a microestrutura do material. A análise de citotoxicidade confirmou que o material não afetou a atividade metabólica das células L929. Sendo assim, as membranas BNC-COL poderão ser vantajosas quando utilizadas para aceleração do processo de cicatrização de feridas.

\section{REFERÊNCIAS}

BALAKRISHNAN, B.; JAYAKRISHNAN, A. Self-cross-linking biopolymers as injectable in situ forming biodegradable scaffolds. Biomaterials, v. 26, n. 18, p. 3941-3951, 2005.

BRETT, D. A review of Collagen and Collagen-based Wound Dressings. Wounds, v.20, n. 12, p. 347-356, 2008.

CHOI, Y.; AHN, Y.; KANG, M. S.; JUN, H. K.; KIM, I. S.; MOON, S. H.. Preparation and characterization of acrylic acid-treated bacterial cellulose cation-exchange membrane. $J$. Chem. Technol. Biotechnol., v. 79, p. 79-84, 2004.

CZAJA, W. K.; YOUNG, D. J.; KAWECKI, M.; BROWN, R. M. The future prospects of microbial cellulose in biomedical applications. Biomacrocolecules, v. 8, n. 1, p. 1-12, 2007.

FIELD, F.K.; KERSTEIN, M.D. Overview of wound healing in a moist environmment. The American Journal of Surgery, v. 167, n. 1 ${ }^{\text {A }}$, p. 2S-6S, 1994.

International Organization for Standardization, "Biological Evaluation of Medical Devices Part 5: Tests for In Vitro Cytotoxicity," Iso 10993-5., vol. 5, pp. 1 - 52, 2009. 


\section{Congresso Brasileiro de Engenharia Química \\ em Iniciação Científica \\ UFSCar - São Carlos - SP \\ 16 a 19 de Julho de 2017}

KLEMM, D.; KRAMER, F.; MORITZ, S.; LINDSTRÖM, T.; ANKERFORS, M.; GRAY, D.; DORRIS, A. Nanocelluloses: A new family of nature-based materials. Angew. Chem. Int. Ed., v. 50, n. 24, p. 5438-66, 2011.

KUMAR, V.; YANG, T. HNO3/H3PO4-NANO2 mediated oxidation of cellulose Preparation and characterization of bioabsorbable oxidized celluloses in high yields and with different levels of oxidation. Carbohydr. Polym., v. 48, n. 4, p. 403-412, 2002.

KWAK, M. H.; KIM, J. E.; GO, J.; KOH, E. K.; SONG, S. H.; SON, H. J.; KIM, H. S.; YUN, Y. H.; JUNG, Y. J.; HWANG, D. Y. Bacterial cellulose membrane produced by Acetobacter sp. A10 for burn wound dressing applications. Carbohydr. Polym., v. 122, p. 387-398, mai. 2005.

LEE, C. H.; SINGLA, A.; LEE, Y. Biomedical applications of collagen. Int. J. Pharm. v. 221, n. 1, p. 1-22, 2001.

LI, W.; GUO, Y.; WANG, H.; SHI, D.; LIANG, C.; YE, Z.; QING, F.; GONG, J. Electrospun nano fibers immobilized with collagen for neutral stem cells culture. J. Mater. Sci.: Mater. Med., v. 19, p. 847-854, 2008.

LIU, T. Y.; LIN, W. C.; HUANG, L. Y.; CHEN, S. Y.; YANG, M. C. Hemocompatibility and anaphylatoxin formation of protein-immobilizing polyacrylonitrile hemodialysis membrane. Biomaterials, v. 26, n. 12, p. 1437-1444, 2005.

LU, T.; LI, Q.; CHEN, W.; YU, H. Composite aerogels based on dialdehyde nanocellulose and collagen for potential applications as wound dressing and tissue engineering scaffold. Compos. Sci. Technol., v. 94, p. 132-138, 2014.

MUANGMAN, P.; OPASANON, S.; SUWANCHOT, S.; THANGTHED, O. Efficiency of microbial cellulose dressing in partial-thickness burn wounds. J. Am. Col. Certif. Wound Spec., v. 3, p. 16-9, 2011.

PAYNE, K. J.; VEIS, A. Fourier Transform IR Spectroscopy of Collagen and Gelatin Solution: Deconvolution of the Amide I Band for Conformational Studies. Biopolymers, v. 27, p. 1749-1760, 1988.

RAMBO, C. R.; RECOUVREUX, D.O.S.; CARMINATTI, C.A.; PITLVANCIV, A.K.; ANTÔNIO, R. V.; PORTO, L. M. Template assisted synthesis of porous nanofibrous cellulose membranes for tissue engineering. Mater Sci Eng C, v. 28, n. 4, p. 549-554, 2008 .

SOUZA, D. J. de. Incorporação de colágeno de rã-touro em membranas de nanocelulose visando aplicação em medicina regenerativa. 2015. 115 f. Dissertação de Mestrado Universidade Federal de Santa Catarina, Florianópolis, Santa Catarina.

TROVATTI, E.; SERAFIM, L. S.; FREIRE, C. S. R.; SILVESTRE, A. J. D.; NETO, C. P. Gluconacetobacter sacchari: An efficient bacterial cellulose cell-factory. Carbohydr. Polym., v. 86, n. 3, p. 1417-1420, 2011. 